\title{
COMO A ARTE (CONTEMPORÂNEA) SE APRESENTA? SOBRE A ATUALIDADE DE A MOLDURA DE GEORG SIMMEL
}

\author{
How does (contemporary) art presents itself? On the current uses of The \\ Frame by Georg Simmel
}

Glaucia Villas Bôas'

\begin{abstract}
Resumo
0 artigo retoma o ensaio "A moldura" de Georg Simmel, publicado em 1902 no jornal berlinense Der Tag, com o propósito de examinar a noção de arte contemporânea a partir das categorias de todo e parte, heterodoxia e autonomia, distância e proximidade, enquadramento e ausência de limite inscritas no texto do autor. Diante das transformações do campo artístico, provocadas pelo desmantelamento dos cânones da arte, as ideias de Simmel parecem retrógradas, ultrapassadas e fadadas ao esquecimento. Em "A moldura", ele ressalta a autonomia e 0 distanciamento da obra de arte, sua natureza desinteressada e sua entrega ao espectador como dádiva. Além disso, afirma que a moldura é um artefato indispensável à obra de arte tanto quanto um elemento constituinte de uma modalidade específica da visualidade, que fomenta um modo de ver contemplativo. Nada poderia ser mais avesso às atuais políticas de proximidade da arte com o seu entorno e de participação efetiva do espectador na obra ou processo artístico; tanto a moldura como a contemplação há muito foram questionadas, perdendo o seu sentido e valor. Argumenta-se, contudo, que as ideias centrais do escrito simmeliano são pertinentes, atuais e relevantes para se pensar questões sociológicas contemporâneas da arte, uma vez que é no jogo entre isolamento e distância do mundo, afastamento e proximidade, autonomia e heterodoxia que a arte - inclusive a contemporânea - se mantém, se apresenta e recria a si própria.
\end{abstract}

Palavras-chave: Arte contemporânea; moldura; Georg Simmel; autonomia e heterodoxia; proximidade e distância.

\begin{abstract}
This paper addresses Georg Simmel's essay "The Picture Frame", published in 1902 in the Berliner newspaper Der Tag, in order to examine the notion of contemporary art having recourse to his categories of the whole and the part, heterodoxy and autonomy, distance and proximity, framing and absence of limit. In view of the transformations in the artistic field provoked by the dismantling of art canons, Simmel's ideas seem to be old fashioned and doomed to be forgotten. In "The Picture Frame", he highlights the autonomy and distance of the art work, its disinterested nature, and its offering to the audience as a gift. Moreover, he points out that the frame is an artifact indispensable to the work of art, inasmuch as it constitutes a specific kind of visuality which stimulates a contemplative way of seeing. Nothing could be farther away from art's current politics of proximity to its surroundings and of participation of the audience in the work or in the artistic process; both the frame and contemplation have long been questioned, thereby losing their purpose and value. I argue, nonetheless, that the main
\end{abstract}

1 Professora titular do Departamento de Sociologia da Universidade Federal do Rio de Janeiro. Email: glauciavboas@gmail.com. 
ideas in Simmel's essay are still current and relevant to think sociologically about contemporary art, since it is in the play between isolation and distance to the world, detachment and proximity, autonomy and heterodoxy that art - including contemporary art - maintains, presents, and recreates itself.

Keyword: Contemporary art; frame; Georg Simmel; autonomy e heterodoxy; proximity e distance.

Não é tarefa fácil retomar o ensaio de Simmel sobre "A moldura" em contexto de desmantelamento das concepções canônicas da arte, no qual um processo veloz de artificação $o^{2}$ transforma os mais diversos objetos e ações em arte, exigindo sua entrada nos museus, a exemplo do grafite, do hip hop e dos coletivos. A contingência do objeto artístico - agora muitas vezes validado pela fotografia, como é o caso de instalações e performances - opõese de uma vez por todas à materialidade e à duração da obra de arte. O que dizer de sua aura? Quem garante sua autoria? Nesse cenário de mudança, tensão e pluralidade, são muitas as combinações das formas artísticas, destacando-se, entretanto, a ênfase nos processos criativos em detrimento do próprio objeto artístico. Amplia-se, assim, o emaranhado de uma rede de artistas, cujo movimento insiste nos gestos de transgressão e politização das expressões artísticas.

Nada poderia ser mais avesso à unidade plácida da obra de arte em seu isolamento, tal como a concebe Simmel em "A moldura. Um ensaio estético", publicado em 1902. Ao contrário do que o autor formula acerca da autonomia da obra de arte e de seu desligamento do entorno pulsante de energias em conexão, uma forte tendência contemporânea pretende ligar arte e vida", como se ela tivesse que descer de seu pedestal, imiscuindo-se no mundo como um objeto entre tantos outros, não mais para ser contemplado ritual e religiosamente, mas para retirar o espectador de sua conformidade passiva, provocando-lhe reações das mais inesperadas, arrancando-o finalmente de sua zona de conforto ${ }^{3}$.

Não é de agora essa movimentação no campo das artes visuais. Ela vem ocorrendo ao menos desde a década de 1960, quando críticos e artistas

\footnotetext{
* Agradeço a Arthur Oliveira Bueno pelas sugestões para a elaboração desse artigo bem como a Ligia Dabul pela oportunidade de discuti-lo em mesa redonda realizada no $18^{\circ}$ Congresso de Sociologia, ocorrido em Brasília, julho de 2017.

2 Para o conceito de artificação ver Shapiro (2007) e Heinich, Shapiro (2012)

${ }^{3}$ Expressão utilizada por artistas, curadores e outros agentes do mundo artístico que significa retirar o espectador de sua suposta passividade.
} 
já propugnavam uma nova concepção de arte como ação e uma "nova política para o espectador", que o encorajasse a participar das manifestações artísticas. Não se escondia a natureza política dos processos artísticos, contrários à autonomia da obra e à submissão do espectador ao objeto de arte. E por mais que se tentasse apaziguar o ânimo dos descontentes com a nova proposta estética, argumentando que a prática contemplativa tinha seu teor político e relacional, não houve como conter a fermentação dos protestos (ERBER, 2015, p. 1-11). Nas últimas décadas, ocorreu uma radicalização daquelas propostas a ponto de se pensar "a arte como trabalho e vice-versa" (PUCU, 2017). As tentativas de explicação para tal acontecimento, no âmbito da arte, vão desde o fim da guerra fria e a globalização até a precarização do trabalho e a desestruturação das hierarquias nas esferas da família e do trabalho (SHAPIRO, 2007); elas incluem ainda abordagens de caráter individualizante que, ao relembrar a imagem do artista romântico e genial, a ela opõem o artista sensivel aos acontecimentos de um mundo conflitado, que não deseja mais isolar-se em seu ateliê para criar uma obra única.

É justamente nesse contexto de efervescência do campo artístico que as publicações dos ensaios de Georg Simmel sobre visualidade e artes plásticas aparecem com maior frequência e, em diferentes idiomas, suas ideias sobre artistas, obras de arte, cidade e paisagens ganham espaço nos debates acadêmicos. Não que tenham uma relação imediata com a discussão sobre a arte contemporânea; ao contrário, o ressurgimento das obras de Simmel se deve a fatores diversos, inclusive aqueles aliados a uma agenda sociológica cujos temas e abordagens têm maior afinidade com a sociologia do autor, temática que ainda está por merecer estudos mais aprofundados ${ }^{4}$. Com maior frequência se atribui a acolhida do pensamento simmeliano, a partir dos anos de 1980, aos estudos e interpretações do inglês David Frisby, que, além de disponibilizar ao púbico de língua inglesa A Filosofia do Dinheiro, em 1978, vislumbrou afinidades das concepções de cultura e modernidade do autor com as discussões sobre a pós-modernidade

\footnotetext{
4 Acrescente-se aqui a publicação das obras completas de Simmel, na Alemanha, a partir de final da década de 1980, sob a direção de Othmar Rammstedt.
} 
(LICHTBLAU, 1992, p. 798-800), realçando entre elas a recusa da ideia de totalidade, a fragmentação do tempo e a estética do estilo de vida moderno.

Chamo a atenção para uma possível conexão dos ensaios simmelianos e a arte contemporânea justamente porque os textos interpretativos dos ensaios sobre cultura e arte, que aparecem paralelamente às publicações dos textos do autor, escritos por sociólogos, historiadores, antropólogos e filósofos, demonstram pouco interesse em colocar em diálogo as ideias de Simmel com as concepções e práticas atuais da arte, mas se limitam a interpretá-las nos seus próprios termos ou cotejá-las com as de outros sociólogos. No seu conjunto, essas interpretações corroboram o modo de pensar corrente sobre a sociologia simmeliana, considerando-a mais filosófica que instrumental e, consequentemente, pouco proveitosa para a pesquisa empírica, o que garante a permanência das ideias do autor em um nicho no qual são reverenciadas e evocadas, sempre que preciso, para ilustrar algumas das "grandes" questões da modernidade.

No caso específico de "A moldura", algumas interpretações recentes se repartem em duas orientações. Na primeira delas, "A moldura" é referência para a análise das proposições de Erving Goffman em Frame Analysis ou mesmo da ideia de Rahmen des Kunstsystems [Enquadramento do sistema da arte] de Niklas Luhmann, procedendo-se neste caso a uma aproximação das proposições de Simmel a dos outros autores, com o objetivo exclusivo de contribuir para a discussão teórica sobre o valor cognitivo das noções de enquadramento, diferenciação e mediação (PLUMPE, 2008, p. 99-108). Essas leituras abandonam qualquer pretensão de adentrar no domínio da arte ou do campo artístico. Em uma segunda direção, os ensaios de Simmel são rastreados na sua inteireza, sendo interpretados e reinterpretados com o propósito de buscar suas filiações filosóficas, sobretudo, indagar se estão atrelados a uma tradição kantiana ou hegeliana ou se pertencem a correntes vitalistas integradas por nomes como Bergson, Nietzsche e Schopenhauer. Tais orientações, entretanto, não se distinguem das interpretações mais 
frequentes do conjunto da obra do autor (VANDENBERGHE, 2005, p. 163$196)^{5}$.

Não pretendo percorrer o ensaio "A moldura", nem tampouco comparar Simmel com outros sociólogos, mas sugerir que suas ideias podem servir de fio condutor para pensar os modos de apresentação da arte, recolocando-as desta forma na agenda dos debates contemporâneos de outra perspectiva. Apesar do interesse crescente pela arte, os modos de sua apresentação nos museus ou fora deles e os valores inerentes aos modos distintos pelos quais a arte se apresenta são raramente tematizados pelos sociólogos. A constatação de que as artes visuais precisam ser exibidas para serem vistas parece simples, e até mesmo simplória, mas de fato não é. As formas de exibição da arte dependem dos mais variados atores sociais, hoje em dia representados pelos curadores de exposição, diretores de museus, arquitetos, designers, engenheiros e técnicos de iluminação, moldureiros, marceneiros, colecionadores, críticos, governantes, banqueiros e empresários.

De outro modo, as formas de apresentação da arte, com ou sem moldura, na parede ou fora dela, no museu ou na rua, revelam diferentes concepções de arte. As molduras trabalhadas em madeira pesada que exibiam quadros da pintura barroca ou acadêmica, pendurados uns sobre os outros na parede, dão lugar a molduras menos rebuscadas, mais lisas, leves e claras que marcam boa parte da arte moderna. Por sua vez, obras ou processos artísticos classificados como arte contemporânea mostram-se ao espectador em instalações, performances, land art que aparecem e desaparecem em esquinas, ruas, praças, parques e florestas afastados dos centros urbanos, fora das paredes do cubo branco ${ }^{6}$. Essas mudanças não só abalaram as estruturas dos museus como espaços de consagração e reconhecimento de artistas como provocaram uma renovação dos interiores dos espaços expositivos tradicionais.

\footnotetext{
5 Neste sentido, vale mencionar Frames, Handles and Landscapes. Georg Simmel and the aesthetics ecology of things de Eduardo de la Fuente (2016, p. 161-184), cuja abordagem se difere das que mencionamos acima, ao se aproximar de uma ecologia dos objetos.

6 Expressão cunhada por Brian O’Doherty para designar os espaços dos museus e galerias de arte moderna, que dá título ao seu livro Dentro del cubo blanco. La ideologia del espacio expositivo, 2011.
} 
Diante das transformações no campo artístico, as ideias de Simmel parecem retrógradas, ultrapassadas e fadadas ao esquecimento. Em $A$ Moldura, ele ressalta a autonomia e o distanciamento da obra de arte, sua natureza desinteressada e a forma de sua entrega ao espectador como dádiva. Além disso, afirma que a moldura é um elemento indispensável à obra de arte tanto quanto um elemento constituinte de uma modalidade específica da visualidade, que fomenta um modo de ver contemplativo, o qual, três décadas depois da publicação do ensaio, teria sido chamada de aurática por Walter Benjamin e perdido seu significado diante das possibilidades de reprodutibilidade das obras. Penso, contudo, que algumas ideias centrais do escrito simmeliano permanecem pertinentes, atuais e relevantes para se pensar questões sociológicas contemporâneas da arte. São elas as ideias de todo e parte, heterodoxia e autonomia, distância e proximidade, enquadramento e ausência de limite. Do meu ponto de vista, é no jogo entre isolamento e distância do mundo, afastamento e proximidade, autonomia e heterodoxia que a arte - inclusive a contemporânea - se mantém, se apresenta e recria a si própria. Por isso, argumento, a seguir, em favor da atualidade do ensaio simmeliano, primeiro repensando as ideias do autor à luz da exposição Acervo em Transformação do MASP/Museu de Arte de São Paulo; segundo, apresentando fatos que evidenciam a quebra ou mesmo o "fim" da moldura; e, finalmente retomando Simmel, uma vez mais, na tentativa de compreender o movimento artístico de juntar arte e vida, a partir das reflexões do próprio autor sobre a modernidade.

\section{A moldura reatualizada}

A multiplicidade das formas de apresentação da arte se faz lembrar aqui através da exposição Acervo em transformação, inaugurada no Museu de Arte de São Paulo, em 2015. Sua curadoria retomou ${ }^{7}$ e reatualizou as ideias pioneiras de Lina Bo Bardi para dispor as obras do acervo permanente do Museu, por ocasião da abertura da sede nova do MASP, em 1968. A arquiteta, responsável pelo projeto do prédio da Avenida Paulista, havia

\footnotetext{
7 Adriano Pedrosa foi o curador da exposição do MASP.
} 
Como a arte (contemporânea) se apresenta? | Gláucia Villas Bôas

concebido um modo original e arrojado de mostrar as obras em cavaletes de vidro (ver imagens 1,2$)$.

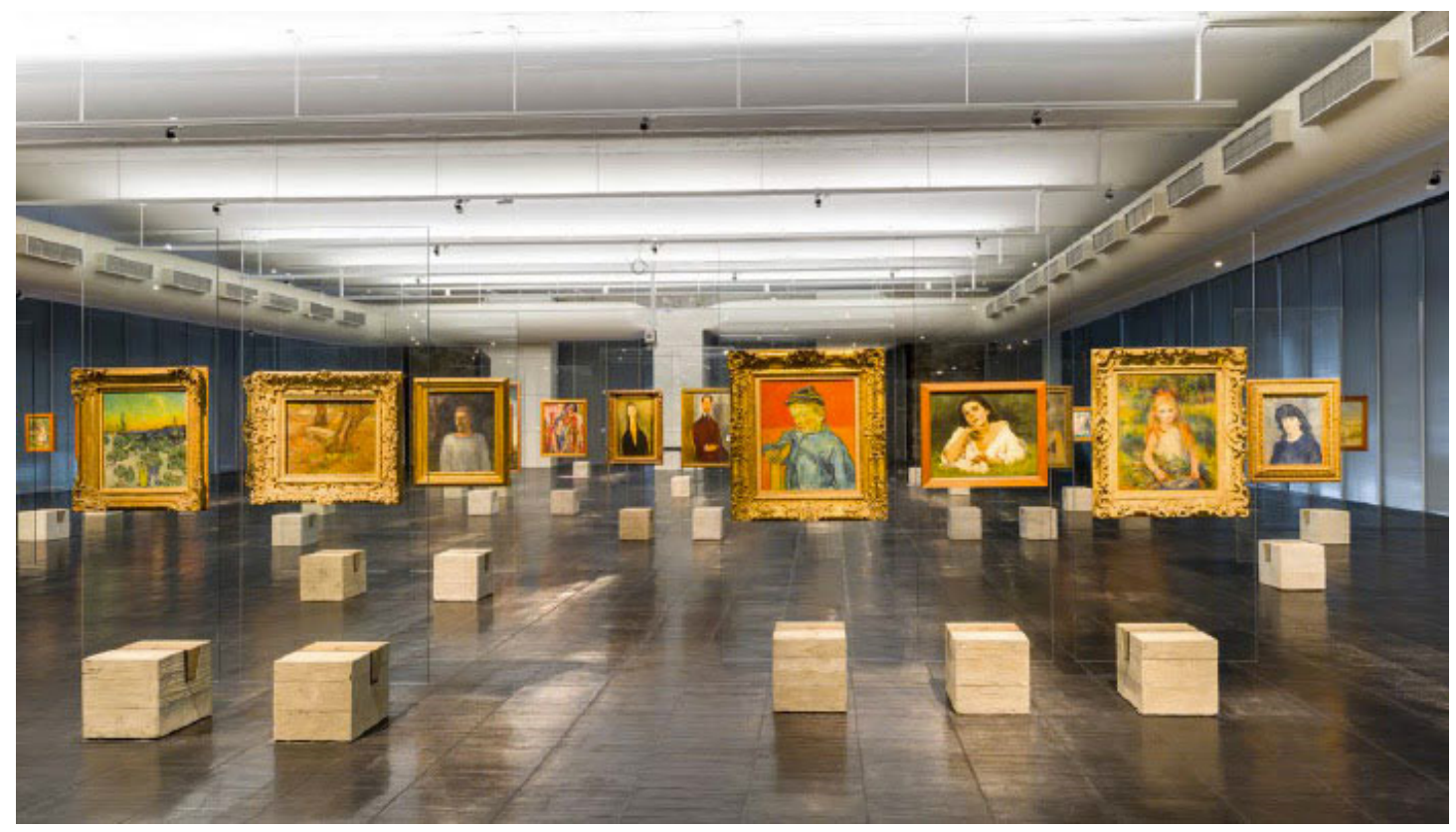

Imagem 1 - MASP 2016, fonte site do museu.

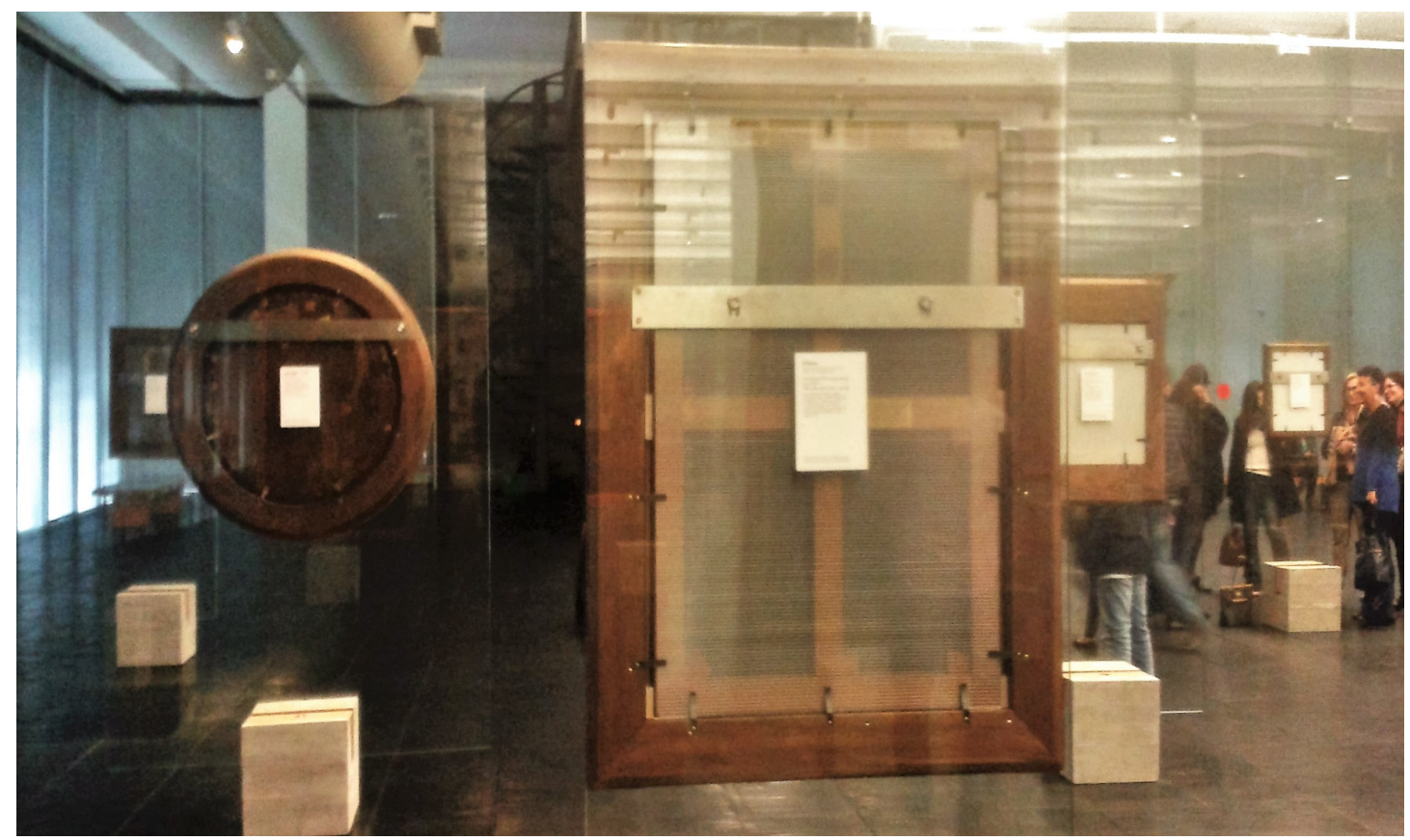

Imagem 2 - MASP. Legenda no chassis, 2006, fotografia de Tálisson Melo.

Acervo em transformação é uma exposição que intervém radicalmente no hábito de ver quadros pendurados em paredes. O espectador pode apreciar as imagens sem nenhuma interferência de legendas e ainda tem a 
chance de buscá-las atrás das molduras, nos chassis que se mostram ao público, provocando um contraste entre aparecimento e ausência da obra. $\mathrm{O}$ corpo passeia pelo espaço da exposição livre das linhas das quatro paredes do recinto, percorrendo sua própria linha e seu desejo de ver. A visita à exposição é por si um convite ao estranhamento, a deixar-se surpreender e indagar pelos hábitos, valores e normas convencionais que presidem as exposições da arte. Porém, o que mais instiga na exposição do MASP é a ousadia de relembrar o cavalete, equipamento desprestigiado pela arte contemporânea, e cujo lugar se circunscreve à pintura tradicional e figurativa, em um ato transgressor que elimina a parede. Eliminar a parede e recuperar os cavaletes, dessa vez de vidro e para serem usados na exibição da obra de arte e não para criá-la, significa conjugar temporalidades diversas, o clássico, acadêmico e o moderno com uma disposição livre de preconceitos e modelos pré-concebidos que afasta as paredes para fazer renascer o cavalete deslocado de seu uso habitual. Agora ele serve para exibir criativamente a obra e não mais para criá-la. Curioso notar, contudo, como a arrojada proposta expositiva manteve os quadros enquadrados em molduras pesadas e ornamentadas, algumas delas douradas e brilhantes, as quais não poderiam desempenhar melhor seu papel de delimitar a unidade das obras no salão do museu.

A visita à exposição do MASP inevitavelmente faz relembrar "A moldura. Um ensaio estético", publicado no Der Tag berlinense. No artigo, Simmel tentava convencer o público do jornal da função da moldura dos quadros de pintura. Não se referia a uma moldura qualquer, mas àquelas que separam as obras de arte de seu redor. A fotografia não carecia de moldura, dizia Simmel, uma vez que, não sendo obra de arte, não se define pelo princípio do encerramento em si, nem estimula o espanto no espectador como a pintura, mas o conduz a uma miriade de outras coisas de natureza histórica, espacial, conceitual ou afetiva com as quais ela está conectada de perto ou de longe. A fotografia "não pertence à ordem ideal da arte, porém, de antemão não quer outra coisa senão conduzir-nos psicologicamente a uma impressão da realidade" (SIMMEL, 1996, p. 36) diria ele mais tarde, em Rembrandt, reafirmando a diferença entre fotografia e arte a que costumava 
referir-se em seus escritos. Ao atribuir autonomia à obra de arte, Simmel lembra que seus limites, diferentes daqueles da fotografia, sempre relacionada com o exterior, exigem e sustentam a moldura, cuja função consiste na "simbolização e afirmação da dupla função dos limites da obra de arte": ela leva à integração da unidade interna da obra de arte por meio da defesa de tudo que lhe é exterior; isolada, a obra reina por si na sua mais absoluta unidade, de onde provém sua força e seu sentido. É daí, diz Simmel, desse recuo em si mesma, que ela se arremessa e penetra mais intensamente no espectador, agraciando-o como uma dádiva (SIMMEL, 2016a, p. 168).

Diversos são os desafios provocados pelo texto simmeliano, sendo um deles seguir de perto o movimento do pensamento do autor, de um objeto eminentemente físico/empírico para as noções abstratas de afastamento e proximidade, unidade e fragmento, existência (de um ser) como todo ou parte e vice-versa. Ao colocar um foco de luz sobre a moldura, Simmel atrai a atenção do leitor para um artefato que, embora acompanhe inúmeras obras de arte, e seja ainda hoje utilizado, certamente perdeu a relevância que teve um dia. O conceito de moldura de Georg Simmel induz o pensamento a refletir sobre o objeto moldura, sua fisicalidade e história, assim como sobre o enquadramento não só de objetos mas das diversas dimensões da vida social, desenvolvendo o tema em direções diferentes, sem deixar entretanto de fazê-las convergir para uma reflexão sobre os limites, as fronteiras e as demarcações em sua dupla função de afastar o exterior/ externo e dar unidade ao interior/interno.

Por isso, Simmel descreve características e tipos de moldura em sua relação com os quadros, lembrando, por exemplo, como pequenos quadros são emoldurados com molduras largas e como as molduras de tecido não são tão adequadas quanto as de madeira porque o tecido "carece daquela estrutura orgânica própria que confere à madeira uma autolimitação tão eficiente e, mesmo assim modesta..." (SIMMEL, 2016a, p 170). Contudo, a análise primorosa da moldura enquanto objeto empírico não se sobrepõe ao problema proposto por ele, mas, ao contrário, é justamente a partir da singularidade e concretude da moldura que o problema fundamental e de 
caráter geral, que diz respeito à existência de seres como um todo ou como parte de um todo, é esclarecido. Essa questão de natureza social e histórica, e não apenas estética, relaciona-se com as ideias de autonomia e heterodoxia que define todos os seres (pessoas e objetos) e não apenas obras de arte. Simmel a retoma ao final do texto quando compara o cavaleiro medieval e o soldado do exército, o artesão autônomo e operário de uma fábrica, o município fechado e a cidade do Estado moderno, a produção caseira e a produção fabril, mostrando a perda da autonomia de atores sociais e comunidades com a chegada da industrialização e da economia monetária (idem, 2016a, p. 172-173). Nesta tensão entre ser um todo (Ganz) dentro de uma totalidade (Ganzheit) vivem todas as partes da totalidade que aspiram ser um todo, como o individuo na sociedade. Não se trata, portanto, de problema de pouca monta o que Simmel apresenta em "A moldura", mas de situação dramática que se apresenta na modernidade. A própria obra de arte enclausurada, seu ser por si mesma, que está no centro da argumentação, é atingida por uma tensão peculiar evidenciada quando o autor compara a moldura moderna e mecânica com a moldura antiga arquitetônica e orgânica, admitindo a tensão da obra de arte - em tempos modernos - proveniente do fato de ser um todo dentro de uma totalidade, como mostrei acima.

$\mathrm{Na}$ exposição Acervo em transformação do Museu de Arte de São Paulo/MASP, mencionada anteriormente, percebe-se que tanto as molduras como os cavaletes e as paredes foram retirados de suas funções tradicionais para exercerem outros papéis: agora o cavalete de vidro serve de suporte para as obras emolduradas, mas dispostas fora das paredes do espaço da exposição, sugerindo que a permanência reatualizada daqueles objetos confere novo sentido à visualidade dos quadros expostos. Na realidade, não se trata de mero deslocamento físico de objetos e sua ressignificação, mas de novo jogo de proximidade e distância que ele propicia entre a obra e o espectador. Ainda que a unidade da obra de arte esteja protegida pela moldura, dando-lhe coesão interna, o fato de estar pendurada em um cavalete de vidro com base de concreto, empresta-lhe o ar de quem saiu de seu lugar habitual para se aproximar ao espectador. Ela não mais recua 
para arremessar-se ao espectador, como afirma Simmel, mas, ao contrário, se aproxima dele, mostrando, de um lado, sua feição de perto e, de outro, seu encerramento em um chassis de madeira. Leves porque soltas das paredes, mas ainda pesadas devido as molduras que as envolvem, as obras de arte expostas no recinto do MASP parecem movimentar-se em torno do corpo que as circunda. De tal modo, as molduras não são suficientes para fazer o olhar convergir para o centro da obra mas a rodear pela frente e por detrás, em círculo ao redor de cada quadro. O visitante serpenteia entre mais de centena de obras, circundando algumas, por qualquer interesse específico. No mais das vezes, ele volta a olhar a obra depois da leitura das legendas com informações sobre o artista e a obra, que ficam atrás do quadro. Essa movimentação do corpo e do olhar faz com que a obra esteja efetivamente mais perto de seu espectador e das "energias" de seu entorno. Acervo em Transformação exemplifica bem as situações da apresentação da arte onde a moldura se faz presente de forma reatualizada, garantindo o isolamento da obra, mas buscando, concomitantemente, aproximá-la do público. Contudo, não apresenta, ainda, a radicalidade das formas de exibição de obras e processos da arte contemporânea.

\section{Com ou sem moldura, dentro e fora do museu}

O fim da moldura não se anuncia somente nas ações e discursos da chamada arte contemporânea. O documentário El Marco (A Moldura) ${ }^{8}$ de 2009 permite avaliar bem o custo do decréscimo da demanda pelas molduras de toda espécie. Elas não foram nem são peças confeccionadas, exclusivamente, para obras de arte a serem expostas em museus, mas de quadros diversos com que milhares de indivíduos adornaram e adornam suas casas e locais de trabalho. No entanto, as imagens produzidas com novas técnicas digitais vêm competindo cada vez mais com as imagens emolduradas, levando à decadência dos negócios. O filme mostra a mudança da fábrica de molduras Francisco Llop, localizada na zona do Raval, em Barcelona, por ordem da Prefeitura da cidade, apresentando depoimentos de operários sobre o desaparecimento do oficio de moldureiro. O deslocamento

\footnotetext{
8 Direção de Marina Pessanha.
} 
da fábrica é o pano de fundo para o ensaio filmico-documental sobre o conceito de enquadrar.

Se quisermos evocar outros acontecimentos de natureza distinta do fechamento da fábrica espanhola, mas diretamente ligados à quebra da moldura, podemos rever a publicação de dois pequenos textos de Lygia Clark sobre a linha orgânica, escritos em 1954 e 1956. Em suas pesquisas, a artista observou uma linha entre a tela e a moldura, circundando o quadro. A experimentação com essa linha, que chamou de orgânica, uma vez que era uma fissura a revelar o interior do corpo do quadro, fez com que ela buscasse, pouco a pouco, incorporar a moldura como elemento plástico no espaço da pintura9 . Ao trazer o "dentro" e o "fora" para o quadro, Lygia questiona a própria estrutura da pintura e acaba formulando um "vocabulário", como dizia, adequado à expressão de um novo espaço. Ela deixa então o plano bidimensional para criar os Bichos (1960), estruturas metálicas geométricas que se movimentam por meio de dobradiças, e cuja finalidade, segundo a artista, era deixar o objeto artístico ao alcance do espectador, contrariando a mera contemplação com o intuito de mudar os hábitos perceptivos tradicionais. Em seguida, ela dá outro passo decisivo, ao conceber Caminhando, em 1963. A artista recusa o objeto artístico para propor ações a serem experimentadas por quem quer que seja, onde e quando desejar, separando-se definitivamente dos espaços, suportes e papéis convencionais do meio artístico. Quando se observa de perto a delicada movimentação das experimentações estéticas de Lygia Clark, notase seu empenho em superar o isolamento e o enclausuramento da obra de arte, buscando formas diversas de experiência com o corpo dos participantes, a exemplo de Baba Cósmica (1973) para evitar que sua obra se tornasse um "espetáculo", no qual a participação estaria sempre negada aos espectadores. O catálogo Lygia Clark. The Abandonment of Art, 1948-1988, publicado para a exposição retrospectiva de sua obra, realizada no MOMA/Museum of Modern Art de Nova York em 2014, revisita as etapas do percurso criativo da artista, sugerindo no seu título a passagem da arte para

\footnotetext{
9 As obras Descoberta da Linha Orgânica (1954), Composição n. 4, Série Quebra da Moldura (1954), Planos em Superficie Modulada (1954) são exemplos preciosos da experimentação de Lygia Clark com a linha orgânica.
} 
a não arte de Lygia. O título provoca controvérsias uma vez que a não arte de Lygia, um conjunto de "proposições", como a chamava a artista, abriu as portas para arte contemporânea, mesmo considerando a recusa de Lygia em classificar seu trabalho como performances, instalações ou body art.

Anos depois, ao final da década de 1990, a crítica à autonomia da arte foi bem longe. Inside the White Cube lançou o nome de Brian O'Doherty (2011) nos debates curatoriais pela sua crítica afiada ao encerramento da obra de arte nas paredes limpas e assépticas de museus e galerias modernos. O artista e critico irlandês argumentava que o distanciamento da arte do público espectador não ocorre somente por intermédio da moldura, porém, a permanência insistente daquela concepção de autonomia da obra de arte inscreve-se agora nas paredes das edificações dos museus. Para ele, a história da arte moderna está aprisionada à atmosfera de neutralidade pretendida pelos espaços expositivos que surgem durante o modernismo. Museus e galerias transformam-se em lugares normativos que determinam como o espectador deve conduzir-se e ver, estabelecendo regras sobre a disposição das obras de arte. A parede branca torna-se um espaço de disputa: quanto espaço deve haver entre um quadro e outro? Há espaço suficiente para que o efeito de uma obra termine antes que a visão do espectador se mova para outra obra? A critica de O'Doherty sobre a normatização crescente do espaço expositivo, visando o isolamento da obra de arte como se ela fosse atemporal, certamente não se identifica à concepção simmeliana de autonomia da obra de arte, mas em muito se aproxima dela, ao revelar o quanto o modernismo cuidou de manter a obra de arte à distância do espectador, emprestando-lhe uma aura de eternidade.

Mais recentemente, os historiadores começaram a indagar pela profunda reviravolta no campo da arte. The contingent object of contemporary art, [A contingência do objeto artístico contemporâneo] publicado pela historiadora norte-americana Martha Buskirk em 2005, mostra com perspicácia a quebra radical de padrões artísticos tradicionais como a autoria, a fisicalidade, a originalidade, a duração, o isolamento e a autenticidade. Duas questões propostas pela autora, são importantes aqui. Uma delas diz respeito à apresentação e disposição das obras da arte 
contemporâneas, que devido a sua contingência, a exemplo das performances, entram no museu como fotografia. O registro fotográfico ou filmico de apresentações de coletivos de arte, performances, landart está se tornando o único meio capaz de permitir a apresentação a posteriori de objetos artísticos e garantir sua veracidade. Buskirk se pergunta pelo tipo de evidência que a fotografia pode oferecer. A historiadora relata casos de performances feitas na rua, que não são anunciadas, não têm público nem enquadramento (BUSKIRK, 2005, p. 220). Fotografadas, essas performances estão longe de ter uma correspondência nas imagens. Segundo Buskirk, as fotografias de performances evidenciam apenas que as ações performáticas são essencialmente inverificáveis, estando seu poder somente em evidenciar o quanto é preciso acreditar nas palavras do artista que descreve aquilo que ele disse que fez. A aparição e o desaparecimento súbitos evocam as noções de acaso, efemeridade, contingência que mutatis mutandis se inscrevem no discurso contemporâneo de louvor ao momento presente e de recusa da duração contínua não apenas de objetos artísticos ou não artísticos, mas atividades e ações individuais ou coletivas.

A outra questão refere-se ao fato de objetos artísticos se realizarem unicamente na sua exposição em espaço determinado com cores, luzes e outros dispositivos - quando o contexto que os cerca é indispensável para a sua completude - correm o risco de perderem a autoria quando são desfeitos. Quem poderá remontá-los novamente em outro lugar? O artista ou o curador? Os trabalhos artísticos vendidos como planos ou projetos levantam o problema de quem poderá executar a obra em outro lugar. Somente o artista ou ele pode delegar a realização da obra a um terceiro ou terceiros? De quem seria a autoria, então? A par dos problemas surgidos com o contexto das instalações, os coletivos de arte questionam a autoria individual. Seja qual for a modalidade do afazer artístico, mais uma vez fica evidente o quanto a fotografia tem entrado como um dispositivo que atesta o acontecimento artístico, sua aparição e desaparição.

A partir do que nos apresenta Buskirk, seria conveniente sublinhar o lugar que a fotografia vem alcançando na arte contemporânea. A conhecida peleja criada em torno de sua relação com a pintura, que, aliás, rendeu um 
conjunto volumoso de escritos, geralmente, contrários à atribuição do estatuto de arte à fotografia (BOURDIEU, 2003), aparentemente merece ser revista, à luz da função e do significado que ela vem adquirindo. Mais do que um garante da ocorrência de uma expressão/proposição artística, como adverte Buskirk, a fotografia se torna obra a ser exposta em museus e galerias, no lugar de performances, instalações e intervenções artísticas na natureza de caráter contingente. A questão suscita ao menos uma indagação a respeito da tomada de posição de artistas e críticos contrária às instituições tradicionais do sistema artístico. Em que medida o desejo de fortalecer os processos em lugar dos objetos e a participação do espectador em lugar da contemplação teriam acabado com a pulsão para o distante e duradouro? Como uma imagem pulsante, porque ligada a uma miríade de conexões exteriores de caráter psíquico, histórico e social, e muito próxima portanto de quem a vê, na acepção de Simmel, a fotografia parece mais apropriada do que a moldura para suprir duplamente o desejo de proximidade dos indivíduos modernos e sua ânsia por algo duradouro.

Assim como o processo de desmantelamento das regras tradicionais do afazer artístico, que ocorre juntamente com a quebra da moldura, atribui novo lugar à fotografia, ele se entrecruza com o processo de artificação, definido pela transformação de objetos em objetos artísticos através de seu deslocamento, renomeação, recategorização, mudança institucional e organizacional, patrocínio, consolidação jurídica, redefinição do tempo, individualização do trabalho, disseminação e intelectualização. Enquanto o primeiro movimento desmantela e desordena, o segundo ordena e classifica, criando novas hierarquias. A artificação se distingue pela multiplicidade de instâncias de regulação e reconhecimento, que incluem o público, os jornalistas, os livros e revistas, os colecionadores, os júris, os diretores de galeria ou de festival, as comissões de atribuição de subvenções, as instituições públicas ou privadas que solicitam os artistas, os estatísticos, os historiadores e os sociólogos, as caixas de aposentadorias e de seguro-saúde, os recenseamentos entre outros (SHAPIRO, 2007). Segundo Shapiro, a multiplicidade dessas instâncias, incluindo grupos sociais muito 
diferenciados, confere o estatuto de arte a uma gama diversa e inesperada de objetos e ações.

\section{Ponderando com Simmel}

A leitura de "A moldura" convida a pensar na permanência do jogo entre isolamento e distância, afastamento e proximidade, protagonizado pelos objetos artísticos em um mundo em movimento. A necessidade de estímulos constantes dos individuos modernos, necessários para romper ou ao menos suspender provisoriamente a uniformidade e a monotonia do mundo em que vivem, foi tematizada por Simmel em ensaio sobre as exposições de arte (2016b, p. 159-166). Aparentemente a arte quer, cada vez mais, provocar estímulos e surpreender o espectador, aproximando a obra da "vida". Enquanto processos artísticos contemporâneos prescindem das paredes, objetos do cotidiano são arranjados em suportes que se prendem às paredes. Basta ver Ciranda de Carlos Bevilacqua, um arranjo de sandálias havaianas disposto em círculo, exposto na ArtRio/Feira Internacional de Arte do Rio de Janeiro em 2016. Ao movimentar-se, a arte se torna parte ou todo? Autônoma ou heterônoma? Unidade ou fragmento? Minha hipótese é que quanto maior o intrincado das teias de relações sociais (quanto mais intensa a modernidade), como Simmel mostra magistralmente no capítulo sobre Estilo de Vida em Filosofia do Dinheiro, maior é a necessidade de excitação e estímulos sentida pelos indivíduos de toda sorte. Assim, a arte encerrada na moldura e separada do mundo exterior vai, paulatinamente, através do tempo, se desvencilhando dos acessórios que a deixam distante do espectador para entrar cada vez mais no âmago da "vida". A autonomia da arte se perde, assim, em função da necessidade de sentir tudo mais próximo, e não apenas isso, mas do que já falara Weber sobre a pulsão aquisitiva do indivíduo moderno de ter sempre mais e à sua disposição. Seja física ou simbolicamente, a arte perde sua autonomia. Ela também quer estar conectada - como mencionei acima relativamente à concepção de Simmel - às energias de todo tipo. Em "Sobre exposições de arte", Simmel critica o novo modo de apresentação da arte em galerias, recintos pequenos onde quadros com diferentes conteúdos se encontram muito próximos um 
do outro (BUENO, 2014, p. 115-126). Toda a apreciação que o autor faz das galerias de arte recai sobre o tipo de sensibilidade do moderno homem da cidade, que "depende do estímulo mais tremendo e avassalador a fim de sentir alguma coisa" (SIMMEL, 2016b, p. 163). E justamente por isso, para atender a necessidades dos individuos modernos, a arte se imiscui nos mais inusitados recantos da vida cotidiana. Numa sequência de distância e proximidade, a autonomia da arte varia em função dos reclamos de estímulos e sensações, provocados pelo amortecimento da sensibilidade na vida moderna:

[...] é justamente a especialização dos nossos tempos que gera essa correria de impressão para impressão, essa impaciência no desfrute, a tentativa problemática de concentrar o máximo de estímulos, interesses e gozos em um mínimo de tempo... (SIMMEL, 2016b, p. 161).

A distância já não é mais uma condição para ver mais ou melhor (WAIZBORT, 2000, p. 190-199) porém, é recusada radicalmente em favor da proximidade que excite, estimule e motive um movimento sem fim, o qual, supostamente, apazigue a inquietude e insatisfação.

A análise de Simmel sobre a carência de sensações e impressões, provocada pela vida moderna, e a necessidade permanente de supri-la pode contribuir para a compreensão do desejo de artistas, críticos e curadores de ligar a arte à vida, e, mais do que isso, de

[...] Libertar a arte de seu confinamento em uma esfera especializada, para torná-la uma dimensão da existência de todos e de qualquer um, fazendo da vida uma obra de arte. Em suma, contaminar de mundo os espaços, os materiais e, sobretudo, a fabulação da arte; contaminar de arte, o espaço social e a vida do cidadão comum (ROLNIK, 1999, p. 2).

Tudo indica que críticos, curadores e artistas contemporâneos estão ocupados com o mesmo tipo de indivíduo moderno de que fala Simmel, amortecidos e amordaçados pelo seu moderno estilo de vida, teriam perdido sua capacidade de sentir, pensar, julgar, escondendo-se em zonas de conforto. Se for assim, a leitura de seu ensaio A Moldura não estaria perdida nem o prisma da análise simmeliana poderia ser considerado retrógrado. A diferença entre Simmel e aqueles que agem na cena da arte contemporânea, repousaria tão somente no grau de normatividade e politização, entre o 
diagnóstico simmeliano e as proposições de ação e participação de artistas, criticos e curadores.

Há, porém, uma dificuldade muito frequente na apropriação das ideias do autor que precisa ser esclarecida. Não é comum abrir os olhos para coisas e pessoas do mundo que nos circunda, muito próximo, em seu movimento ininterrupto, sem usar um modelo conceitual fixo e rígido, diante do desafio que a multiplicidade das coisas e os arranjos vários em que elas se combinam nos colocam. Menos comum ainda é deixar-se seduzir pela arte que se faz em processos e objetos artísticos, sem recorrer aos ensinamentos da crítica, dos educativos, do que escrevem os curadores em legendas e catálogos, das explanações dos historiadores de arte e dos filósofos da estética. Muito embora sejam muitos os argumentos em favor da diversidade das interpretações, a verdade é que há uma força repressora a colocar todas as intenções em um longo trilho. Quando, então, Simmel ensina em $A$ Moldura a pensar no movimento e nas demarcações do movimento, no fechar-se e abrir-se, em ser parte ou todo, autônomo ou heterônomo, não estaria ele, possibilitando finalmente, uma alternativa para se pensar a obra de arte fora de uma moldura conceitual rígida? Pedro Erber afirma que

De Platão a Kant e Hegel, de Schiller a Adorno e Ranciére, o discurso da estética é, fundamentalmente, um discurso sobre a moldura; ele circunscreve a arte dentro de uma esfera específica, definindo suas fronteiras e suas interações com outras dimensões da prática social (ERBER, 2015, p. 90).

Simmel não foge à regra. Para que o caráter transgressor de seu pensamento apareça, a partir da leitura de A Moldura, é preciso, antes de mais nada, colocar à margem sua concepção de autonomia da arte (portanto o conteúdo do ensaio) para atentar para o modo específico e singular com o qual seu pensamento opera no conhecimento de seu objeto a partir das noções de distância e a proximidade, autonomia e a heterodoxia. Só assim a aventura de retomar o ensaio de Simmel para pensar a arte contemporânea ganharia sentido.

\section{Referências}

BOURDIEU, Pierre. Un Arte Medio. Ensayo sobre los usos sociales de la

fotografia. Barcelona: Editorial Gustavo Gili, 2003. 
BUENO, Arthur Oliveira. As Economias da Vida. Dinheiro e Arte como formas de vida nos escritos de Georg Simmel. Tese de doutorado, USP, 2014.

BUSKIRK, Martha. The Contingent Object of Contemporary Art. Massachusetts: MIT Press, 2005.

BUTLER, Cornelia H.; PÉREZ-ORAMAS; Luis; CLARK, Lygia. The Abandonment of Art, 1948-1988. New York: The museum of Modern Art, 2014.

CLARK, Lygia, A descoberta da linha orgânica [Online]. In: FIGUEIREDO, Luciano. (org.) Livro-Obra. 1956. Disponivel em: $<$ http: / issuu.com/lygiaclark/docs/1954-descoberta-da-linhaorganica_p/3?e $=0>$

ERBER, Pedro. Breaching the Frame. The Rise of Contemporary Art in Brazil and Japan. California: University of California Press, 2015.

FUENTE, Eduardo de la. Frames, handles and landscapes. Georg Simmel and the aesthetics ecology of things. In: KEMPLE, Thomas; PYYHTINEN, Olli (orgs). The Anthem Companion to Georg Simmel. London: Anthem Press, 2016.

HEINICH, Nathalie; SHAPIRO, Roberta (orgs). De 1'artification. Enquêtes sur le passage à 1'art. Paris: EHESS, 2012.

LICHTBLAU, Klaus. Rezension zu: David Frisby, Simmel and Since. Essays on Georg Simmels Social. In: Kölner Zeitschrift für Soziologie und Sozialpsychologie, v. 44, 1992.

O'DOHERTY, Brian, Dentro del cubo blanco. La ideologia del espacio expositivo. Murcia: Centro de Documentación y Estudios Avanzados de Arte Contemporaneo (Cenoeac), 2011.

PESSANHA, Marina. E1 Marco, filme documentário, 24 min. 2008.

PLUMPE, Gerhard. Rahmen - Vermittlung zwischen Werk und Welt? In: Kritische Berichte. Zeitschrift fuer Kunst und Kulturwissenschaft, 4, 2008.

PUCU, Izabela, Arte como trabalho (e vice-versa). UFRJ, EBA, 2017.

ROLNIK, Sonia, The Experimental Exercise of Freedom: Lygia Clark, Gego, Mathias Goeritz, Hélio Oiticica e Mira Schendel. Los Angeles: The Museum of Contemporary Art, 1999.

SHAPIRO, Roberta. O que é artificação? In: Sociedade e Estado, Brasília, v. 22, n. 1, 2007. 
SIMMEL, Georg. A Moldura. Um ensaio estético. In: VILLAS BÔAS, Glaucia; OELZE, Berthold (orgs.). Georg Simmel: Arte e Vida Social. Ensaios de estética sociológica. São Paulo: Hucitec Editora, 2016a.

. Sobre exposições de arte. In: VILLAS BÔAS, Glaucia; OELZE, Berthold (orgs.). Georg Simmel: Arte e Vida Social. Ensaios de estética sociológica. São Paulo: Hucitec Editora, 2016b.

Rembrandt. Ensayo de Filosofia del arte. Murcia: Colegio de Aparejadores y Arquitetos técnicos, 1996.

VANDENBERGHE, Frédéric. As Sociologias de Simmel. Bauru, SP: EDUSC; Belém: EDUPFA, 2005.

WAIZBORT, Leopoldo. As Aventuras de Georg Simmel. São Paulo: USP, Editora 34, 2000. 